\title{
It's Not Only about Technology, It's about People: Interpersonal skills as a Part of the IT Education
}

\author{
Ricardo Colomo-Palacios ${ }^{1}$, Cristina Casado-Lumbreras ${ }^{2}$, \\ Ángel García-Crespo ${ }^{1}$, and Juan Miguel Gómez-Berbís ${ }^{1}$ \\ ${ }^{1}$ Universidad Carlos III de Madrid, Computer Science Department \\ Av. Universidad 30, Leganés, 28911, Madrid, Spain \\ \{ricardo.colomo, angel.garcia, juanmiguel.gomez\}@uc3m.es \\ Karakorum Servicios Profesionales \\ C. Zurbarán 5, Pozuelo de Alarcón, 28223 Madrid, Spain \\ ccasado@karakorumsp.es
}

\begin{abstract}
The importance of what have been termed the "soft skills" for the professional development of IT professionals is beyond any doubt. Taking account of this circumstance, the objective of the current research may be phrased as two separate questions. In the first place, determining the importance which IT related degree students place on these types of competencies for their professional future. In the second place, the importance which the development of the mentioned competencies has been given during their studies. The realization of an empirical study has fulfilled the two objectives described. The results demonstrate, on the one side, the moderate relevance which students assign to interpersonal competencies, especially emotional competencies, in contrast to the international curricular recommendations and studies concerning labor markets. On the other hand, the results indicate the scarce emphasis which lecturers have placed on the development of such competencies.
\end{abstract}

Keywords: Soft Skills, IT Education, Interpersonal skills, Emotional competences.

\section{Introduction}

The concept of social or interpersonal abilities refers to the social competencies or capacities which people possess. However, this concept, which is generally perceived as rather simple, has been captured in numerous definitions. In the presence of such an abundance of definitions, Linehan's [1] definition can be selected as a base for the present study. Interpersonal skills are "the complex capacity to exhibit behavior or response patterns which optimize interpersonal influence and resistance to undesired social influence (efficiency in both objectives), which simultaneously maximizes gains and minimizes the losses in the relationship (efficiency in the relationship) and maintains one's own integrity and sense of domain (efficiency with respect to oneself)". Lazarus [2] was one of the first authors to establish the principal response or behavioral dimensions which characterize social skills from a clinical perspective: 1) The capacity to say "no", 2) The capacity to ask for favors and make requests, 3) The capacity to express positive or negative feelings and 4) The capacity to initiate, 
maintain, and finish conversations. The response classes outlined above are based on the four category types proposed by Lazarus [2]. In this sense, specifically with respect to the Information, Communication and Technology field, interpersonal skills are considered general and necessary for professionals [3], and employers at international level consider interpersonal skills as a key aspect for recent graduates from the technical area [4].Taking into account the unquestionable importance of interpersonal skills, the concept of competency related to this aspect has been included in curricular initiatives in diverse disciplines. Competences can be defined as an individual's core skills (motives, traits, self-concept, knowledge, and abilities) that are causally related to a specific, effective criterion and/or a superior performance at work [5].

Particularly within the domain of IT related degrees, curricular initiatives are being developed for the set of five fields which includes: Software Engineering [6], Computer Engineering [7], Information Systems [8], Information Technology [9] and Computer Science [10], which as a set have been given the generic name Computing Curricula 2005. These proposals are jointly sponsored by a committee comprised of the IEEE and ACM. In addition to the five volumes mentioned, a study is currently being realized which draws together and compares aspects of the diverse proposals [11]. This publication emphasizes the importance of interpersonal communication, which includes aspects such as written and oral communication, presentation, interaction with clients, sales activities, and their comparison across different disciplines. With this objective in mind, minimum and maximum values from 1-5 on a Likert-type scale have been included for the weight which interpersonal communication should be assigned within the categories mentioned. The values presented are the following: Computer Engineering (3.4), Computing (1.4), Information Systems (3.5), Information Technology (3.4) and Software Engineering (3.4).The scores assigned indicate that considerable importance has been attributed to the interpersonal communication category across all of the distinct disciplines. The most comprehensive analysis of interpersonal skills may be found in the volume dedicated to Information Systems [8].

A second aspect worth mentioning is the inclusion of interpersonal skills within the set of capacities of graduates. In this case, interpersonal skills form part of the category "interpersonal, communication and team skills" and have four associated behaviors: listening, encouragement, motivation and operating in a diverse environment. The specification of interpersonal skills both as part of the body of knowledge as well as the capacities of graduates has initiated, as a third notable characteristic, its inclusion within the programs of various subjects recommended in the curriculum for graduates of the discipline. The study which has been develop which will be described in what follows, consisted of exploring the judgments of young people regarding the importance they give to interpersonal skills in their suture professional career. The particular case under analysis in the current paper is a study directed exclusively towards IT related degrees students about to complete their degree, whose incorporation in the labor market is evident.

Traditionally, it has been assumed that the organizational practice of the IT professional does not require mayor skills in the interpersonal domain. The professional reality has demonstrated that the IT professional requires the development of skills which go beyond the management and application of a series of technical aptitudes, whether he is a coder, team leader or manager. 


\section{Interpersonal Skills as a Research Field in IT}

Today soft skills represent a wide study area in the IT field. In [12], it was affirmed that the most important skills for new IT professionals were soft skills. Other authors have drawn more refined conclusions, and consider that soft skills are more important than technical skills for less experienced IT personnel [13],[14]. In contrast, opposing views to this research [15], [16] state that technical skills are of a higher importance than soft skills. Finally, other works claim that technical and behavioral skills are likely to be complementary [17]. Leaving aside the relative importance of soft skills of professionals at any level in the IT field, the necessity to possess interpersonal skills, one of the soft skills, is without doubt. However, this reality, which IT professionals are familiar with, in confronted by the professional stereotype. This stereotype for IT professionals includes anti-social [18] and solitary [19], to name but a few. However, this stereotype, which is found in many media such as cinema [20] and television [21], is far from being certain.

Examining at study carried out between academics and professionals in the IT field [22], both groups indicate that, behind personal traits, interpersonal skills are the second most important factor for professional practice. It is also interesting to note that IS academics rate interpersonal skills, less important than IS practitioners do, while IS academics deem the variables in the IS technology area as important as or more important than IT practitioners do. This gap was already demonstrated in the 1990s in [23]. Other studies [24] in the same area, however realized among IT students, indicate that technical skills are important but are not sufficient within themselves, and need to be complemented with other skills such as communication and interpersonal skills. Furthermore, other studies completed in High School environments indicate that the opinions of the students with relation to interpersonal skills are closer to the stereotype [25]. Independently of the professional stereotypes of the different IT roles which the IT professional may adopt, the importance of interpersonal skills is highly notable. [26] provides a detailed description of the skills in the context of the different IT roles.

To summarize, some authors indicate that universities must not only include in their curriculum the hard skills of technical expertise, but also the soft skills of interpersonal communication, intrapersonal knowledge, leadership and collaborative skills that lead to a cohesive team [27].

\section{The Study}

The present study has consisted of the analysis of the importance which students in the final year of a Computer Engineering degree place on soft skills, particularly, interpersonal skills, for their professional future. In order to achieve this objective, a questionnaire has been applied in which the various interpersonal skills have been characterized with 18 associated behaviors. The application of the questionnaire had a double objective. In the first place, to quantitatively determine the opinions of the students with respect to interpersonal skills in the context of professional life, as well as their opinion of the importance which was placed on such skills during their higher education. In the second place, it was aimed to examine whether or not there were statistically significant differences in the responses according to gender. The subsequent sections detail the sample, the questionnaire applied, as well as a discussion of the results obtained. 


\subsection{Sample and Questionnaire}

The present study has been developed based on the participation of 92 students in their final year of a Computing Engineering degree from several universities in Madrid (Politécnica de Madrid, Carlos III de Madrid, Autónoma, Pontificia de Salamanca, Pontificia de Comillas y UNED). The sample was composed of a total of 22 women (24\%) and 70 men (76\%).This gender difference is caused by the uneven proportion of men versus women enrolled in the course. The average age of the students was established as 25.7 years.

The questionnaire was comprised of 18 questions or items which describe behavior or competencies. These items collectively formed the category "Interpersonal Skills". The items selected for inclusion in the questionnaire were chosen based on the integration of 12 response classes, which are generally accepted as basic social skills in the Psychology field, with other items whose descriptions are more oriented towards a work environment. The respondents were requested to indicate the importance of the skills using a Likert-type scale, on which the value 1 indicated "of no importance", and the value 4 indicated the opinion "very important". Additionally, the students were elicited for their perceived importance of the different skills in the context of their academic career, based on what was communicated to them by their lecturers. The scale described above was also used to indicate scores in this case.

\subsection{Results and Discussion}

With the objective of determining the scores obtained for each element, an average and standard deviation was calculated for the results obtained in relation to the relative importance of the scores. The results are demonstrated in Table1.

Table 1. Average and Standard Deviation of the perceived importance of elements

\begin{tabular}{|c|c|c|}
\hline Element & Average & Std Dev. \\
\hline Capacity to accept compliments & 1,55 & 0,58 \\
\hline Capacity to make compliments & 1,60 & 0,54 \\
\hline $\begin{array}{l}\text { Capacity to express annoyance, discomfort or anger } \\
\text { in a justified way }\end{array}$ & 1,68 & 0,57 \\
\hline Capacity to recognize the emotions of others & 1,84 & 0,77 \\
\hline Capacity to express appreciation or affection & 1,85 & 0,77 \\
\hline Capacity to reject requests of other people & 1,85 & 0,78 \\
\hline $\begin{array}{l}\text { Capacity to perceive the reactions of others to our } \\
\text { own actions or opinions }\end{array}$ & 1,88 & 0,81 \\
\hline Capacity to admit ignorance about something & 1,98 & 0,81 \\
\hline $\begin{array}{l}\text { Capacity to request a change in the behavior of } \\
\text { another person }\end{array}$ & 2,00 & 0,80 \\
\hline Capacity to accept the help of others & 2,00 & 0,85 \\
\hline Capacity to take into account the opinions of others & 2,05 & 0,91 \\
\hline Capacity to make one's opinion be heard & 2,18 & 0,95 \\
\hline $\begin{array}{l}\text { Capacity to express personal opinions, including } \\
\text { disagreement }\end{array}$ & 2,20 & 0,97 \\
\hline Capacity to make requests in an adequate fashion & 2,22 & 0,84 \\
\hline Capacity to excuse oneself & 2,25 & 0,94 \\
\hline $\begin{array}{l}\text { Capacity to accept constructive criticism regarding } \\
\text { one's own behavior }\end{array}$ & 2,27 & 0,96 \\
\hline Be capable of listening with attention & 2,46 & 0,87 \\
\hline Capacity to initiate and maintain conversations & 2,48 & 0,84 \\
\hline
\end{tabular}


Examining the results, it is possible that the stereotype of the IT professional has distorted the importance of the competences for the students in a similar effect to the influence of this stereotype on the rest of society. Several studies have identified the stereotypes of IT Professionals [18], [19], [20], [21]. These stereotypes accentuate negative characteristics of professionals such as anti-social or solitary, to name but a few. Thus, Table 2 below displays the results of the perceived importance by the students of the skills, but in relation to the emphasis placed on such skills during their university career:

Table 2. Average and Standard Deviation of the perceived importance of Interpersonal Skills elements during higher education degree

\begin{tabular}{|c|c|c|}
\hline Element & Average & Std Dev. \\
\hline Capacity to accept compliments & 1,24 & 0,43 \\
\hline Capacity to make compliments & 1,26 & 0,44 \\
\hline $\begin{array}{l}\text { Capacity to express annoyance, discomfort or anger } \\
\text { in a justified way. }\end{array}$ & 1,28 & 0,45 \\
\hline Capacity to recognize the emotions of others & 1,14 & 0,35 \\
\hline Capacity to express appreciation or affection & 1,17 & 0,38 \\
\hline Capacity to reject requests of other people & 1,70 & 0,64 \\
\hline $\begin{array}{l}\text { Capacity to perceive the reactions of others to our } \\
\text { own actions or opinions }\end{array}$ & 1,33 & 0,52 \\
\hline Capacity to admit ignorance about something & 1,52 & 0,58 \\
\hline $\begin{array}{l}\text { Capacity to request a change in the behavior of } \\
\text { another person }\end{array}$ & 1,30 & 0,46 \\
\hline Capacity to accept the help of others & 1,47 & 0,64 \\
\hline Capacity to take into account the opinions of others & 1,90 & 0,88 \\
\hline Capacity to make one's opinion be heard & 1,95 & 0,87 \\
\hline $\begin{array}{l}\text { Capacity to express personal opinions, including } \\
\text { disagreement }\end{array}$ & 1,95 & 0,87 \\
\hline Capacity to make requests in an adequate fashion & 1,62 & 0,74 \\
\hline Capacity to excuse oneself & 1,26 & 0,44 \\
\hline $\begin{array}{l}\text { Capacity to accept constructive criticism regarding } \\
\text { one's own behavior }\end{array}$ & 1,29 & 0,46 \\
\hline Be capable of listening with attention & 2,18 & 0,89 \\
\hline Capacity to initiate and maintain conversations & 2,39 & 0,91 \\
\hline
\end{tabular}

An initial analysis of the scores, examining both the importance of the skills in general, as well as the emphasis placed on the skills during university studies, indicates the discrepancy between both analyses. However, it is interesting to note that the "Capacity to initiate and maintain conversations" is the most valued capacity, and additionally, the capacity which students considered was assigned the most importance during their entire third level career. It is evident that almost all of the skills demonstrated low scores in relation to the attention they were given during students' university studies. Consequently, there is a large gap between the importance of the skills for the students, and the perceived importance which was placed on such skills during their academic career.

From the perspective of gender differences, the average displayed by the groups of the relative importance of the skills in Table 1 was almost always higher for the female 
category. In order to measure the level of statistical significance of this difference, the researchers applied the Students' $T$ test. This statistical method, comparison of two means, was used to carry out one-way between-groups analysis of variance (ANOVA). The level of statistical significance was set at 0.05. Table 3 displays the competencies which demonstrate statistically significant differences between both groups:

Table 3. Significant differences between the importance of elements according to gender

\begin{tabular}{ll}
\hline Element & Test \\
\hline Capacity to recognize the emotions of others & $(\mathrm{t}(21)=-2,21, \mathrm{p}<.05)$ \\
$\begin{array}{l}\text { Capacity to express appreciation and affection } \\
\text { Capacity to reject requests from others }\end{array}$ & $\mathrm{t}(21)=-2,434, \mathrm{p}<.05)$ \\
$\begin{array}{l}\text { Capacity to perceive the reactions of others to one's } \\
\text { own acts or opinions }\end{array}$ & $(\mathrm{t}(21)=-3,215, \mathrm{p}<.05)$ \\
$\begin{array}{l}\text { Capacity to admit ignorance about something } \\
\text { Capacity to elicit a change in the behavior of another }\end{array}$ & $(\mathrm{t}(21)=-2,978, \mathrm{p}<.05)$ \\
$\begin{array}{l}\text { person } \\
\text { Capacity to accept the help of others }\end{array}$ & $(\mathrm{t}(21)=-2,978, \mathrm{p}<.05)$ \\
$\begin{array}{l}\text { Capacity to take into account the opinions of others } \\
\text { Capacity to make requests in an adequate fashion }\end{array}$ & $(\mathrm{t}(21)=-3,078, \mathrm{p}<.05)$ \\
$\begin{array}{l}\text { Capacity to excuse oneself } \\
\text { Capacity to accept constructive criticism about one's }\end{array}$ & $(\mathrm{t}(21)=-2,628, \mathrm{p}<.05)$ \\
own behavior & $\mathrm{t}(21)=-2,090, \mathrm{p}<.05)$ \\
Be capable of listening with attention & $(\mathrm{t}(21)=-2,090, \mathrm{p}<.05)$ \\
Capacity to initiate and maintain conversations & $(\mathrm{t}(21)=-2,731, \mathrm{p}<.05)$ \\
\hline
\end{tabular}

Examining the table displayed above, it can be seen that female students are more sensitive to the importance of interpersonal skills than male students, as significant differences emerged between both samples. This outcome supports the results of previous studies which indicate that as a general rule, women have abilities superior to those of men in expressing and communicating emotions towards others, as has been demonstrated by numerous authors e.j. [28].

\section{Conclusions}

Summarizing the results of the current study, the findings indicate that the opinions of students and thus future IT professionals do not correspond to the proposals in curricular initiatives, nor to the increasing importance assigned to such skills in a professional environment. While young people principally minimize the importance of emotional competencies except for those which could be considered communication competencies in a more strict sense, academic and professional literature is attributing increasingly greater importance to emotional competencies. It can be concluded that likewise, the students generally do not perceive the importance placed on such skills during their university studies.

In this environment, institutions and teaching professionals in engineering disciplines should foster the awareness, learning and development of these key competencies for successful professional performance, even prior to the implementation of such 
recommendations in practice. It can be affirmed that both professionals as well as lecturers are not effectively communicating the professional reality of the IT professional. In order to achieve this, both professional associations as well as those in the academic field should be encouraged to establish effective communication and education measures to obtain the outcome that students, on the one hand, receive improved training in social competencies, and on the other hand, perceive these competencies with high esteem for a professional role.

\section{References}

1. Linehan, M.M.: Interpersonal effectiveness in assertive situations. In: Bleechman, E.A. (ed.) Behavior modification with women. Guilford Press, New York (1984)

2. Lazarus, A.A.: On assertive behaviour: A brief note. Behavior Therapy 4, 697-699 (1973)

3. Lee, C.K.: Transferability of Skills over the IT Career Path. In: Proceedings of the 2005 ACM SIGMIS CPR conference on Computer personnel research, pp. 85-93 (2005)

4. Gruba, P., Al-Mahmood, R.: Strategies for Communication Skills Development. In: Proceedings of the sixth conference on Australian computing education, vol. 30, pp. 101107 (2005)

5. Spencer, L.M., Spencer, S.M.: Competence at Work. Models for Superior Performance. Willey and Sons, New York (1993)

6. Software Engineering. Curriculum Guidelines for Undergraduate Degree Programs in Software Engineering (August 23, 2004)

7. Computer Engineering. Curriculum Guidelines for Undergraduate Degree programs in Computer Engineering, Final Report. IEEE Computer Society \& ACM (December 12, 2004)

8. Gorgone, J.T., Davis, G.B., Valacich, J.S., Topi, H., Feinstein, D.L., Longenecker, H.E.: IS 2002, Model Curriculum and Guidelines for Undergraduate Degree Programs in Information Systems (2002)

9. Computing Curricula, Information Technology Volume, Draft (April 2005)

10. Computing Curricula 2001. Computer Science. Final Report, (December 15, 2001)

11. Shackelford, R., Davies, G., Impagliazzo, J., McGettrick (eds.): Computing Curricula 2004. The Overview Report. Draft, (November 22, 2004)

12. McMurtrey, M.E., Downey, J.P., Zeltmann, S.M., Friedman, W.H.: Critical Skill Sets of Entry-Level IT Professionals: An Empirical Examination of Perceptions from Field Personnel. Journal of Information Technology Education 7, 101-120 (2008)

13. Kovacs, P.J., Caputo, D., Turchek, J., Davis, G.A.: A survey to define the skill sets of selected information technology professionals. Issues in Information Systems Journal 7(1), 242-246 (2006)

14. Young, D.: The relative importance of technical and interpersonal skills for new information systems personnel. Journal of Computer Information Systems 36(4), 66-71 (1996)

15. Lee, S., Yen, D., Havelka, D., Koh, S.: Evolution of IS professionals' competency: An exploratory study. Journal of Computer Information Systems 41(4), 21-30 (2001)

16. Koong, K.S., Liu, L.C., Lui, X.: A study of the demand for information technology professionals in selected internet job portals. Journal of Information Systems Education 13(1), 21-28 (2002)

17. Litecky, C., Arnett, K., Prabhakar, B.: The paradox of soft skills versus technical skills in IS hiring. The Journal of Computer Information Systems 45(1), 69-76 (2004) 
18. Martin, C.D.: Is Computer Science a profession? ACM SIGCSE Bulletin 30(2), 7-8 (1998)

19. Craig, A., Paradis, R., Turner, E.: A Gendered View of Computer Professionals: Preliminary Results of a Survey. ACM SIGCSE Bulletin 34(2), 101-104 (2002)

20. Colomo-Palacios, R., Gómez-Berbís, J.M., García-Crespo, A.: IT Professionals: The Seventh Art Perspective. Novatica 187, 58-61 (2007)

21. García-Crespo, A., Colomo-Palacios, R., Gómez-Berbís, J.M., Tovar-Caro, E.: IT Crowd, Are we just Stereotypes? IT Professional 10(6), 24-27 (2008)

22. Lee, S., Koh, S., Yen, D., Tang, H.L.: Perception gaps between IS academics and IS practitioners: an exploratory study. Information \& Management 40(1), 51-61 (2002)

23. Trauth, E.M., Farwell, D.W., Lee, D.: The IS expectation gap: Industry expectations versus academic preparation. MIS Quarterly 17(3), 293-307 (1993)

24. Medlin, B.D., Dave, D.S., Vannoy, S.A.: Students' views of the importance of technical and non-technical skills for successful IT professionals. The Journal of Computer Information Systems 42(1), 65-69 (2001)

25. García-Crespo, A., Colomo-Palacios, R., Gómez-Berbís, J.M., Tovar-Caro, E.: IT Professionals' Competences: High School Students' Views. Journal of Information Technology Education 8(1), 45-57 (2009)

26. Feeny, D.F., Willcocks, L.P.: Re-designing the IS Function around Core Capabilities. Long Range Planning 31(3), 354-367 (1998)

27. Woodward, B.S., Ashby, S., Litteken, A., Zamora, S.: Student Perceptions of Information Technology Preparedness and Important Job Skills. Information System Journal 6(38) (2008)

28. Schwartz, G.E., Brown, S.L., Ahern, G.L.: Facial muscle patterning and subjective experience during affective imagery: Sex differences. Psychophysiology 17, 75-82 (1980) 